\title{
O GESTO DO ARQUIVO: ENTREVISTA COM AS ANTROPÓLOGAS \\ PROFA. DRA. CORNELIA ECKERT \\ E PROFA. DRA. ANA LUIZA CARVALHO DA ROCHA
}

\author{
Fabiana Bruno ${ }^{1}$ \\ Óscar Guarín Martínez ${ }^{2}$
}

Não seria arbitrário pensar que os arquivos de imagens ocupam um lugar de relevância na história da Antropologia. Basta considerarmos que desde a consolidação das imagens técnicas, entre os séculos XIX e XX, os documentos visuais integram de maneira atuante a história da etnografia e da Antropologia e representam na atualidade - mais de dois séculos depois - uma produção acumulada em arquivos.

Inúmeros são os $\operatorname{artigos}^{3}$ publicados que dedicaram-se a reconstituir os gestos antropológicos vinculados à visualidade - como a fotografia e o filme - que levaram a inauguração dos primeiros passos de uma chamada Antopologia Visual. O registro do antropólogo em campo, por exemplo, demarcou um gesto fotográfico na história da etnografia. A famosa expressão "eu estive lá" definia-se por um ato fotográfico que, se por um lado testemunhava a presença do etnógrafo no campo, por outro constituía um legado de documentos visuais, os quais, na contemporaneidade, nos remetem a uma história das imagens e em imagens da Antropologia.

Fotografias deste gênero são bastante conhecidas como aquelas de Bronislaw Malinowski, nas Ilhas Trobiand, ainda no início do século XX. Arquivos como estes na

\footnotetext{
${ }^{1}$ Universidade Estadual de Campinas, Brasil. Email: fabybruno@uol.com.br ORCID id: https://orcid.org/0000-0002-2826-4628

${ }^{2}$ Pontifícia Universidad Javeriana, Colômbia. Email: guarino@javeriana.edu.co ORCID id: https://orcid.org/0000-0003-2475-028X

${ }^{3}$ Para fazer referência a apenas alguns deles: Samain, Etienne. "No fundo dos olhos: os futuros visuais da antropologia". Samain, Etienne. In: Cadernos de antropologia e imagem, Rio de Janeiro, UERJ, $\mathrm{n}^{\circ}$ 6, p. 141-158, 1998 e do mesmo autor "Ver e dizer na tradição etnográfica. Bronislaw Malinowski e a Fotografia". Horizontes Antropológicos, Porto Alegre, ano 1, n. 2, p. 23-60, jul./set., 1995; JEHEL. Pierre-Jérôme. "Fotografia e antropologia na França no século XIX". Cadernos de Antropologia e Imagem, n. 6, p. 123-37, 1998. Ver ainda Caiuby Novaes, Sylvia na apresentação do livro Entre arte $e$ ciência: a fotografia na antropologia. São Paulo: Edusp, 2015, 224p. O livro organizado pela autora é uma coletânea de artigos que reúne pesquisadores interessados nos usos da imagem fotográfica na Antropologia.
} 
atualidade sugerem amplas e potentes reflexões que não mais se restringem meramente a aquela que esteve dedicada a uma datação e registro da ida de Malinowski ao campo, especialmente se combinados, revisitados e desdobrados em suas possíveis e inesgotáveis relações com outros tantos documentos capazes de fazer pensar a história. Sylvia Caiuby Novaes escreveu em 1999 um artigo ${ }^{4}$ sobre a relação entre LéviStrauss e a fotografia demonstrando, sob outra perspectiva, como a imagem conquistou uma dimensão relevante nas obras de Claude Lévi-Strauss, como técnica de registro que acompanhava seu caderno de campo, embora o próprio antropólogo não tenha ressaltado - e nem mesmo reconhecido diretamente - a importância da fotografia em seus trabalhos antropológicos. As imagens e seus arquivos, havemos de não ignorar, quando abertas em sua complexidade e temporalidades, permitem configurar e reconfigurar outras formas de ver e pensar antropologicamente.

Etienne Samain escreveu um artigo cujo título e propósito são bastante instigantes: “Quando a fotografia (já) fazia os antropólogos sonharem: O jornal La Lumière (18511860) (2001). No texto, ele reflete como já na efervescente metade do século XIX a fotografia e a Antropologia partilhavam e trocavam "sonhos e realidades" (2001; 90). Samain faz uma exegese do jornal francês La Lumière $^{5}$, primeira publicação francesa dedicada à "Fotografia, às Artes e às Ciências", publicado entre os anos de 1851 e 1867 e parcialmente reimpresso em 1995. Neste artigo, apresenta o contexto da metade do século XIX, que, nas palavras de Etienne Samain, era "marcada pela febre da ordem e do progresso, da racionalidade e das luzes" para evidenciar como "os antropólogos-

\footnotetext{
${ }^{4}$ Refiro-me ao artigo "Lévi-Strauss, razão e sensibilidade", publicado na Revista de Antropologia vol. 42, n. 1-2, São Paulo, 1999. Parte das fotografias de Lévi-Strauss produzidas durante suas pesquisas etnográficas no Brasil foi publicada em Tristes trópicos (1955) e no álbum Saudades do Brasil (1994).

${ }^{5}$ Para ter uma ideia do que teria sido o La Lumière, remetemos ao que escreve Samain: "La Lumière foi a primeira publicação francesa dedicada à fotografia. A primeira a alimentar um debate que, desde a divulgação da sua invenção (1839), a fotografia não cessou de levantar - situada que estava, na encruzilhada de "três polos de interesses contraditórios": as Belas Artes, as Ciências e a Indústria. Durante exatos 17 anos, de 1851 a 1867, La Lumière dará conta deste debate, apaixonante e múltiplo, no meio de suas próprias vicissitudes editoriais, reestruturações e tensões internas. Passados 150 anos, podese imaginar que este monumento dos arquivos fotográficos permanecia, na sua totalidade, de difícil encontro e reconstrução. Existiam, aqui e acolá, exemplares anuais incompletos." (2001, 89-90). La Lumière era apresentado, conforme escreve Samain, como Jornal não Político e de Belas-artes, Heliografia, Ciências e teve sua primeira publicação em Paris, num domingo, 9 de fevereiro de 1851. A publicação foi dirigida, segundo Samain, num primeiro momento, pelo coronel Benito de Montfort e pelo padre F. Moigno.
} 
naturalistas franceses descobrem, ao lado de muitos outros cientistas, as possibilidades heurísticas que a fotografia ofereceria à 'visão' que eles tinham da 'Antropologia', a saber essa tentativa de mapeamento da 'espécie humana', das raças e, dentre elas, dos tipos humanos, numa perspectiva claramente evolucionista" (2001; p.89).

Samain propõe uma reflexão sobre estes vínculos entre as origens da Antropologia francesa e a descoberta da fotografia para pensar como uma nova ordem do olhar levanta outras questões em termos de uma epistemologia do conhecimento. Ele interroga: "qual será, nos quadros de uma Antropologia que, hoje, questiona o imperialismo da verbalidade na elaboração de seu discurso, o lugar da imagética num mundo onde, em toda parte, a imagem se faz presente? De que imagens e de que suportes imagéticos precisaremos para entender os homens e as sociedades que se constroem com elas?” (2001; p.111).

No século XXI vivendo entre acúmulos de imagens que se formam aos montes, estamos diante de outros desafios. Entre eles, o de como enfrentar os excessos e atribuir sentidos ao visual nas culturas para compreender os mundos a partir das nossas próprias relações com imagens e entre imagens. Estes desafios também implicam outros modos de gerar as produções antropológicas, os arquivamentos e os compartilhamentos de imagens. Compartilhar e tornar imagens acessíveis estendem na atualidade os desafios antropológicos no contexto da chamada cultura da visualidade.

A Antropologia, por meio de sua abordagem de pesquisa para além de um compromisso destinado unicamente aos domínios históricos de uma ciência arquivística, ocupa na atualidade um lugar fundamental para a crítica dos arquivos de imagens, pois atua fundamentalmente numa perspectiva de desmontagem destas imagens e de desdobramentos de narrativas, memória e na imaginação em direções contrahegemônicas.

As antropólogas professoras Dra. Cornelia Eckert (UFRGS) e Ana Luiza Carvalho da Rocha (UFRGS e FEEVALE) indagam nesta entrevista como não se reconhecer a importância da produção científica com imagens nos dias de hoje? A proposta do BIEV (Banco de Imagens e Efeitos Visuais) - criado em 1997 no âmbito do Laboratório de Antropologia Social (NAVISUAL/PPGAS, UFRGS) - é pioneira nesta modalidade de trabalho em plataforma digital, na qual Eckert e Rocha atuaram na idealização e desenvolvimento do projeto. Trata-se de uma constelação de arquivos visuais disponível por meio de plataformas digitais. "Para nós importava alimentar o processo de 
construção de narrativas a partir das novas tecnologias da informática para conceber, no âmbito da pesquisa etnográfica, formas de indexação, de catalogação e de cadastramento dos conjuntos documentais etnográficos (...) Nosso esforço era criar um museu virtual com este acervo", relatam Eckert e Rocha em entrevista.

Os experimentos do BIEV são reconhecidos como uma etnografia hipertextual e situam-se no uso do método de convergência para a formação de coleções etnográficas em multimídias interativa. O referencial teórico incorpora e desdobra os supostos de uma etnografia da duração e em especial utilizando-se da noção de modelização para pensar os arranjos das imagens. "Neste procedimento de modelização, a matéria das lembranças não está orientada para a manutenção das formas do passado, mas, ao contrário, provoca a consciência do vazio e do nada. No processo de modelização da memória, e conforme a etnografia da duração, a matéria das lembranças só atinge o status de duração quando a situamos num complexo de ordenações múltiplas que ligam as imagens umas às outras. Logo, a modelização para nós carrega o problema da tradução do fenômeno da consolidação temporal no tratamento de coleções etnográficas, nos moldes propostos pelas tecnologias digitais e eletrônicas", revelam as antropólogas.

Autores magistrais como Gaston Bachelard e seus discípulos como Gilbert Durand são as importantes referências que trouxeram ao BIEV e à trajetória de seus projetos e pesquisas, inspirações teóricas acerca da memória, da duração, do tempo e do imaginário. O projeto do BIEV teve para a sua implantação e desenvolvimento financiamento da Fapergs e do CNPq e apoio do PPGAS, IFCH e UFRGS.

Em entrevista sobre estes questionamentos (leia na íntegra, nesta publicação), Eckert e Rocha sugerem que a importância dos arquivos para a disciplina antropológica pode ser resumida com o fato que arquivar é um gesto de construção de um patrimônio da humanidade, de resguardo de memórias vividas, além de tornar-se uma narrativa importante sobre o pensamento e a ação humana e não humana. Ambas são uníssonas ao expressarem a reflexão que a Antropologia dá movimento reflexivo e interpretativo para esta materialidade escrita, imagética ou artesanal. 


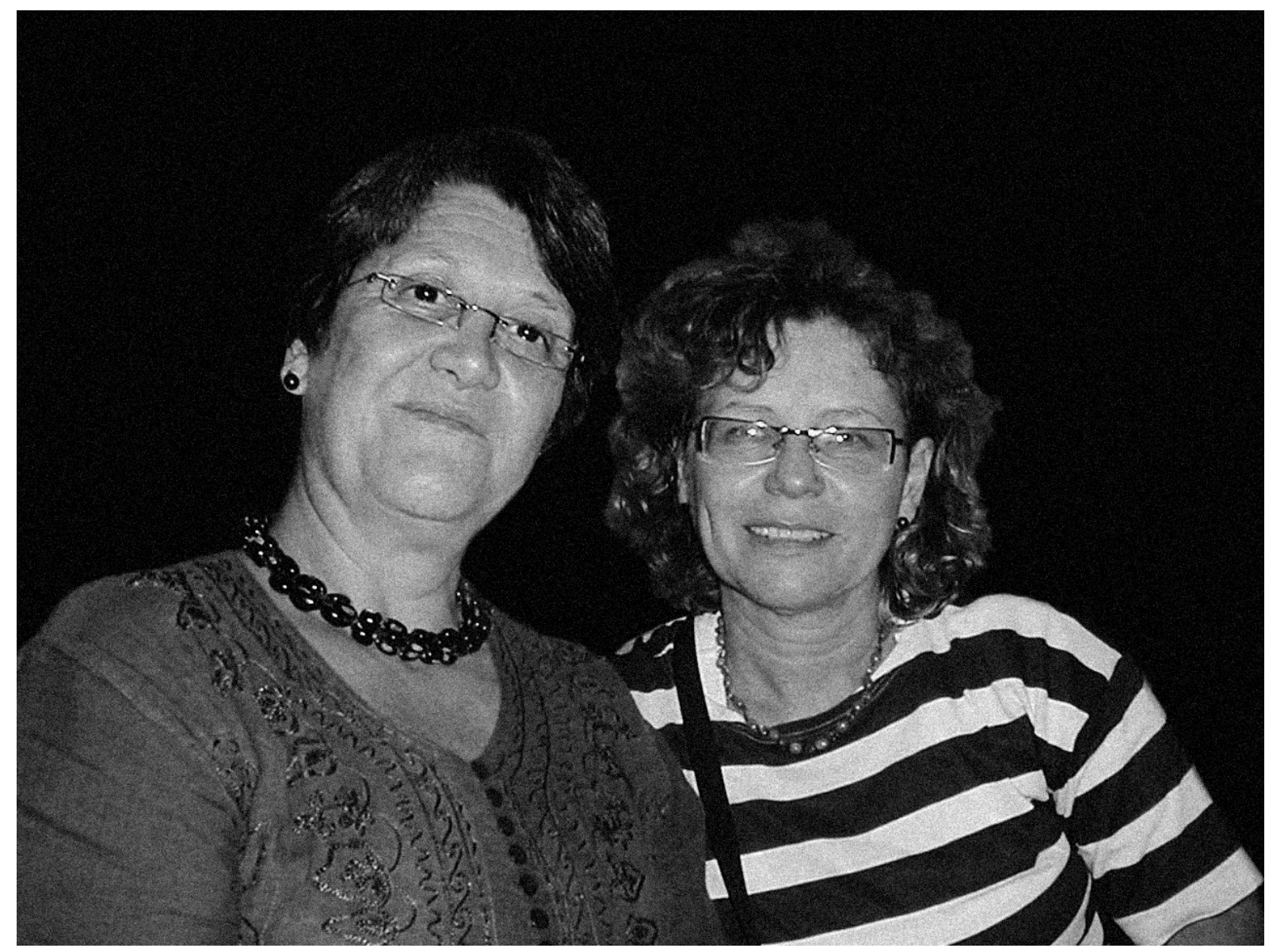

Figura 1: As antropólogas Profa. Dra. Ana Luiza Carvalho da Rocha e Profa. Dra. Cornelia Eckert

Fabiana Bruno e Óscar Guarín Martínez: Desde que a história da Antropologia passou a reconhecer o campo de uma chamada Antropologia Visual no Brasil, constata-se alguns movimentos de revisitação de seus estatutos. Fala-se em uma Antropologia Visual, mas também em uma Antropologia Audiovisual ou em uma Antropologia das Imagens, muitas vezes, como questões sinônimas. O que define uma ou outra nomenclatura? Haveria importantes distinções? De que tipo?

Cornelia Eckert e Ana Luiza Carvalho da Rocha: A Antropologia, pelo menos até os anos 1980, se caracterizou por uma disciplina de palavras como dizia Margareth Mead em artigo datado de 1975. Mead criticava uma disciplina que transforma palavras ouvidas e ações observadas em textos escritos. Mas também é verdade que desde os pais e mães fundadores da Antropologia moderna, como a obra de Malinowski (Os argonautas do Pacifico Ocidental) de Bateson e Mead (Balinese character. A photo analysis) ou Evans Pritchard (Os Nuers), para exemplificar alguns clássicos, a 
Antropologia vem incorporando mapas, gráficos, fórmulas matemáticas, a fotografia, o filme e o gravador como forma de registro e exposição dos dados de campo, tanto quanto forma de comunicação de suas etnografias.

Em 1975, no artigo citado, Visual Anthropology in a Discipline of Words' in Principles of Visual Anthropology, Margareth Mead atenta para a importância das visualidades no exercício etnográfico e na interpretação e evoca a terminologia Antropologia Visual. Esta terminologia passou a ser consenso para a definição imediata de uma linha de pesquisa ou área de estudo com produção de imagens.

Com o aprimoramento dos filmes etnográficos e a sincronia do som, por exemplo na obra de Jean Rouch, além da consolidação da etnomusicologia ou Antropologia sonora, outras terminologias foram demandadas para dar conta da complexidade das pesquisas e do desenvolvimento técnico: Antropologia Audiovisual, Antropologia Sonora. A Antropologia da Imagem emerge sobretudo a partir da sofisticação das teorias do imaginário.

No Brasil, em determinado momento das políticas de fomento, o CNPq solicitou que os antropólogos em visualidades definissem uma terminologia técnica para identificação da área para fins de política de fomento. A rede de Antropologia que atuava neste campo definiu por Antropologia Visual como um termo guarda-chuva sem grandes conflitos. Para além disso, cada projeto de pesquisa tem a liberdade de criar subáreas na plataforma Curriculum Lattes do CNPq. Desta forma podemos encontrar várias definições nas subáreas para contemplar as pesquisas com técnicas e suportes diversos como Antropologia Digital, Nanoetnografia, Antropologia Sonora, Antropologia e arte. Todas acabam por, ao mesmo tempo, definir uma rede de pesquisadores com possíveis diálogos e trocas, por outro lado, pode engessar as ações de pesquisa que podem ser muito mais plurais e diversas do que o termo define. Mas estas definições são dinâmicas e se transformam conforme a demanda dos pesquisadores.

Bruno e Guarín: Como os estudos e problematizações metodológicas sobre as singularidades de trabalho com as imagens avançaram ao longo das décadas no campo da Antropologia Visual? Qual é a importância da interdisciplinaridade nas pesquisas sobre as imagens? E qual lugar a Antropologia Visual ocupa hoje, no âmbito da disciplina da Antropologia? 
Eckert e Rocha: É uma questão muito ampla e poderíamos preferencialmente indicar vários artigos para leitura. Alguns escritos por nós, outros por colegas. Importante para quem estiver interessado no tema perceber que a reflexão sobre os avanços da pesquisa com visualidades é de modo geral acompanhada pelo reconhecimento do desenvolvimento técnico ou tecnológico, tanto quanto da trajetória da própria disciplina perpassando diferentes tradições teóricas e mesmo metodológicas, embora sempre considerando a etnografia como prática dominante do fazer pesquisa. No Brasil, a partir dos anos 1980, temos excelentes produções de periódicos e livros que perfazem estas inter-relações. Como por exemplo o periódico Cadernos de Antropologia e Imagem da UERJ organizado por Patrícia Monte-Mor e Clarice Peixoto, agora extinto, mas acessível em PDF. Os escritos de Etienne Samain, Sylvia Caiuby, Clarice Peixoto, Renato Athias, Carmen Rial, Lisabete Coradini, Marco Antônio Gonçalves, Milton Guran, Fernando de Tacca, Ana Luiza Carvalho da Rocha, Bela Bianco, Miriam Moreira Leite, Gabriel Alvarez, Luiz Eduardo Achutti, Cornelia Eckert, Vincent Carelli e Dominique Gallois, para nos mantermos na produção dos anos 1980 e 1990, entre tantos outros, são muito elucidativos para responder esta sua questão. De nossa parte, os leitores podem encontrar vários artigos sobre este tema na revista que editamos, Revista Iluminuras, acessível no link, https://seer.ufrgs.br/iluminuras .

A importância da interdisciplinaridade se dá, não somente por compartilharmos o conhecimento técnico com várias outras áreas de conhecimento, em especial a técnica do filme, fotografia e som, quanto outras técnicas que não são originárias de nossa área de conhecimento como desenhos, grafias, diagramas e arte de modo geral; mas sobretudo pela partilha de campo teórico e conceitual com áreas coirmãs como sociologia, história, filosofia, linguística, psicologia, política mas também de áreas que são base de teorias antropológicas como a matemática, biologia, fisiologia etc.

Hoje a Antropologia Visual está consolidada como área de conhecimento científico. Em todas as associações de Antropologia no mundo, há comitês de Antopologia Visual. A produção de filmes etnográficos, ensaios fotográficos e audições são contemplados com prêmios nacionais e internacionais. A circulação é fomentada cada vez mais pela facilidade da internet e plataformas abertas. Nossos Programas de Pós-Graduação têm incentivado este campo de pesquisa. Hoje temos concursos específicos nesta área e em praticamente todos os programas encontramos um laboratório, núcleo, centro de pesquisa e formação. Além dos seminários, grupos de trabalho e mesas redondas nos 
mais diversos eventos de impacto nacional e internacional. Como não reconhecer a importância da produção científica com imagens nos dias de hoje? Presentemente somos os imagéticos da Antropologia. A primeira vez que escutamos a alcunha “imagéticos da Antropologia” foi através da ex-presidente da Associação Brasileira de Antropologia (ABA), Bela Feldman-Bianco (2010-2012), referindo-se à rede de pesquisadores em Antropologia Audiovisual vinculados ao Grupo de Estudos de Antropologia Visual, hoje, Comitê de Antropologia Visual da Associação Brasileira de Antropologia. Consideramos o epíteto apropriado para tecer os contornos de uma rede de interesses de pesquisadores que têm em comum a produção e a formação de discentes na pesquisa etnográfica com produção em fotografia, vídeo, som e procedimentos de informatização (DVDs interativos, sites, portais, blogs etc). Hoje o número de dissertações, teses, TCCs que produzem com imagens é significativo. Ainda assim, é verdade, como chama a atenção a colega Clarice Peixoto, que poucos registram sua produção com a palavra-chave ou linha de pesquisa de Antropologia Visual. Temos insistido neste sentido, para fins estatísticos, pois isto implica fomento para a pesquisa nesta área.

Bruno e Guarín: Como as pesquisas com os arquivos de imagens têm ocupado lugar na história da Antropologia Visual? Que importância existe na construção de um pensamento antropológico dirigido aos arquivos?

Eckert e Rocha: Tanto na Antropologia em seus primórdios quando na gênese de tecnologia do mundo moderno (surgimento da fotografia e do cinema) temos a lógica do arquivo de imagens como base de conhecimento. Os estudos com uma perspectiva evolucionista estão diretamente relacionados aos empenhos de uso de aparelhos que permitiam o registro de imagens. $\mathrm{O}$ registro de imagens marca o mundo moderno. Este maquinário surgiu na virada do século XIX para XX. Como o fuzil fotográfico e a cronofotografia relacionados aos esforços de Etienne Jules Marey em 1882, professor de história natural no Collège de France. Na sequência outro inventor, Thomas Edison, e o seu fonógrafo por volta de 1888 e, pouco mais tarde, o kinetoscópio, criando imagens em movimento. Estas imagens registram a existência humana apropriada para sustentar uma ideologia evolucionária como o estudo das raças. Para a análise comparativa, estas imagens são arquivadas em uma coleção de corpos, ossaturas e posturas. Importa citar também outra tradição, quase na mesma época, a da escola 
culturalista tendo por liderança Franz Boas, o grande incentivador da construção de coleções etnográficas que povoam, desde então, os museus culturais no mundo. Veja o quanto o século XIX foi técnica e teoricamente fundante do ato moderno de arquivar as imagens, não só as produzir, mas reproduzir graças as técnicas de cópia que se aprimoram, e inquietam os intelectuais da Escola de Frankfurt em suas teorias críticas sobre a reprodutibilidade e a ameaça à aura da arte. Coleções para representar o mundo em seu progresso linear sedimentaram ideologias, finalmente criticadas na virada liderada pela revolução cultural no século XX.

Sobre a importância dos arquivos para nossa disciplina, podemos resumir argumentando que este é um gesto de construção de um patrimônio da humanidade, de resguardo de memórias vividas. Torna-se uma narrativa importante sobre o pensamento e ação humana e não humana. A Antropologia dá movimento reflexivo e interpretativo para esta materialidade escrita, imagética ou artesanal. Estes atos reflexivos e interpretativos se baseiam em múltiplas e diferentes bases teóricas que não cabe aqui retomar.

\section{Bruno e Guarín: O BIEV tem um pioneirismo no trabalho com a formação de} arquivos visuais em plataformas digitais e no contexto da Antropologia Visual no Brasil. Como essa proposta foi construída em termos de um lugar para formar, pensar e desdobrar um certo estatuto de arquivos?

Eckert e Rocha: O BIEV foi criado por nós em 1997 no âmbito do Laboratório de Antropologia Social (PPGAS, UFRGS). Partimos de um projeto que seguia esquemas enunciativos oriundos dos domínios da Antropologia Urbana e da Antropologia Visual. Buscávamos um espaço de divulgação e de acesso aos usuários das redes mundiais de computadores aos conjuntos documentais versando sobre os acontecimentos vividos por grupos e/ou indivíduos em Porto Alegre (RS), lócus de nossas pesquisas etnográficas. Passamos a formar no âmbito do projeto, pesquisadores e bolsistas com o tema das representações acerca da estética urbana, da memória coletiva e do patrimônio etnológico local. Nosso esforço era criar um museu virtual com este acervo.

Com financiamento da Fapergs e do CNPq e com o apoio do PPGAS, IFCH, UFRGS o BIEV se empenhou em uma pesquisa experimental com as novas tecnologias esta orientada para a criação de um banco de conhecimento sobre memória coletiva e o patrimônio etnológico de Porto Alegre (BIEV-data), e a sua divulgação (BIEV-site), a partir do portal Banco de Imagens e Efeitos Visuais. Para nós importava alimentar o 
processo de construção de narrativas a partir das novas tecnologias da informática para conceber, no âmbito da pesquisa etnográfica, formas de indexação, de catalogação e de cadastramento dos conjuntos documentais etnográficos.

A partir da existência de quatro bases de trabalho segundo as linguagens adotadas para a pesquisa etnográfica na área da Antropologia das sociedades complexas: vídeo, som, fotografia, escrita, elaboramos conjuntos de documentos na forma de coleções etnográficas.

Nosso desafio é de restauração da palavra do Outro pela emergência de uma etnografia hipertextual, que tem nos conduzido a refletir sobre os princípios éticos que orientam o saber-fazer antropológico tradicionalmente produzido na forma de objeto-livro, quando ele é confrontado, não somente aos desafios de se romper um discurso hegemônico sobre o Outro, orientado que está pela defesa da igualdade dos grupos humanos na diferença, e projetado na rede mundial de computadores, na era das textualidades eletrônicas.

\section{Bruno e Guarín: Como o BIEV tem problematizado noções como memória, imaginação e temporalidade no desdobramento de suas pesquisas?}

Eckert e Rocha: Consideramos, seguindo Gilbert Durand em sua obra As estruturas do imaginário, que toda imagem é fruto de um trajeto intelectual que reúne, numa gênese recíproca, os imperativos do sujeito e as intimações da ambiência objetiva. Insistimos em nossas falas e escritos que abraçamos uma fenomenologia compreensiva onde, a partir dos dados etnográficos, conhecemos as imagens pensadas e fabuladas, o que exige do etnógrafo uma ruptura com uma temporalidade fundada meramente na construção de uma historicidade de fatos ou como ilustração. Para pesquisa com memória, imaginação e temporalidade, propomos uma etnografia da duração onde consideramos que toda a imagem remete ao campo do imaginário, o qual é já do domínio do tempo, pois ele pertence ao domínio da memória.

A pesquisa etnográfica com e por meio das imagens, norteada pelo uso das tecnologias aplicada ao estudo da modelização dos jogos da memória na web, proposto pelo BIEV, tem nos permitido repensar o conceito de patrimônio desde a perspectiva de patrimônio etnológico. Estamos em pleno espaço, o das narrativas, como lugar onde o tempo se regenera, um fenômeno que resulta da ação humana no mundo em sua luta por reconciliar as antinomias que implica o tempo. Partindo desta premissa, veremos que o 
processo de produção de etnografias audiovisuais e multimídias no campo da Antropologia das sociedades complexas a partir de coleções etnográficas, e na forma de constelações de imagens, engendra o fenômeno da causalidade da duração, ou seja, da supremacia do tempo desejado sobre um tempo vivido. Sob este ângulo, todo o relato etnográfico comporta a possibilidade de repetição e a liberdade dos começos, tanto para o antropólogo como para os sujeitos de suas pesquisas, ditos "nativos".

Portanto, longe de querermos nos situar fora desta querela, os experimentos que desenvolvemos no BIEV, com etnografia hipertextual, baseados no uso do método de convergência para a formação de coleções etnográficas em multimídias interativas, integram um longo processo de investigação que temos procurado levar adiante sobre o tema da consolidação temporal que preside a dinâmica cultural em sociedades complexas, no âmbito de uma etnografia da duração.

Neste ponto, precisamente, a pesquisa com a modelização dos jogos da memória para o estudo do patrimônio etnológico no mundo urbano contemporâneo trata dos tempos vazios e dos tempos de espera mais do que nos tempos plenos e das certezas, da interrupção de uma ação e sua passagem a outra mais do que sua simples continuidade, pois é através do desencaixe das lembranças de seus quadros de origem que todo o etnógrafo pode interpretar o lugar que elas ocupam na narração de nosso passado. Não como recitação, ou apenas a instrução histórica, mas como devir.

Para o caso da pesquisa do BIEV, empregamos, portanto, o termo modelização para pensar o arranjos das imagens, a um só tempo - os dados etnográficos, antigos e recentes, em mídias diversas (registro fotográfico, videográfico, escrito e sonoro, pictográfico-etc.) -, sobre Porto Alegre e onde a imagem, em vez de ter a pretensão de evocar um tempo passado, dele nos separa. Neste procedimento de modelização, a matéria das lembranças não está orientada para a manutenção das formas do passado, mas, ao contrário provoca a consciência do vazio e do nada. No processo de modelização da memória, e conforme a etnografia da duração, a matéria das lembranças só atinge o status de duração quando a situamos num complexo de ordenações múltiplas que ligam as imagens umas às outras. Logo, a modelização para nós carrega o problema da tradução do fenômeno da consolidação temporal no tratamento de coleções etnográficas, nos moldes propostos pelas tecnologias digitais e eletrônicas. 


\section{Bruno e Guarín: Quais estudos e autores no campo das imagens e arquivos foram e são referências para o trabalho do BIEV e seus pesquisadores?}

Eckert e Rocha: Primeiramente citamos nossa filiação à linhagem da Antropologia urbana ou Antropologia das sociedades complexas. Citemos Eunice Durham, Ruth Cardoso, Gilberto Velho, Ruben George Oliven, Antônio Arantes, entre outros dessa geração, que consolidaram o campo de conhecimento sobre o fenômeno de modernização das cidades brasileiras. Foi no amadurecimento desta geração de antropólogo (as), voltada aos estudos do e no urbano, que nos formamos, aprendendo logo cedo os desafios que a tradicional pesquisa etnográfica exigia para nos habilitar aos estudos das sociedades complexas. Na pesquisa com imagens no Brasil, para nós os precursores recentes são Etienne Samain, Milton Guran, Miriam Moreira Leite, na Antropologia.

Mas no campo da teoria da imagem, seguimos Gaston Bachelard. Em especial seus estudos da memória coletiva que seguem a tese da duração, sugerida em outra obra $A$ dialética da duração. Também nos é cara sua teoria da fabulação, onde relaciona o campo do imaginário ao domínio do tempo, uma vez que este pertence ao domínio da memória. Entre seus discípulos que também nos orientam se destaca Gilbert Durand e sua noção de "trajeto antropológico". Com este autor entendemos que o fenômeno da memória se refere a um conjunto de estruturas fantásticas que configuram as culturas humanas, atuando como conservatórios de seus valores primordiais. Neste ponto, a memória se exprime por meio da função fantástica, o que, no plano do imaginário, significa que ela precisamente manifesta seu poder de criar um lugar em que "as imagens podem permanecer fora do tempo"

Disto resulta que a etnografia da duração comporta o semantismo das imagens expresso nas narrativas dos habitantes das grandes cidades sobre seus territórios de vida. A narrativa revela-se parte integrante (e integradora) dos estudos antropológicos da memória coletiva nas cidades contemporâneas. Por seu intermédio, observamos a angústia existencial que secreta toda cidade em se transformar na expressão rítmica de contrastes de tempos passados e tempos futuros para, finalmente, nascer como essência "estética tecnicamente controlada". Estamos referindo o campo dos estudos sobre memória coletiva à modelagem dos símbolos universais segundo a derivação pedagógica do habitante das grandes metrópoles, nos termos de um "trajeto antropológico". 
Claro que há muitos outros autores que nos são fundamentais para contemplar a hermenêutica contemporânea revelando, para nós, nossa pertença a uma comunidade interpretativa da fenomenologia da memória. Citemos Mauss, Simmel, Halbwachs, Ricoeur, Benjamin, Sansot, De Certeau, Guenon, Morin, Maffesoli, Piault, Rouch, Arlaud, Preloran, Mc Dougall, Bateson para não adentrarmos a teorias decoloniais mais recentes que nos reorientam. Mas adentrar esta comunidade nos levaria a uma extensão cansativa desta resposta.

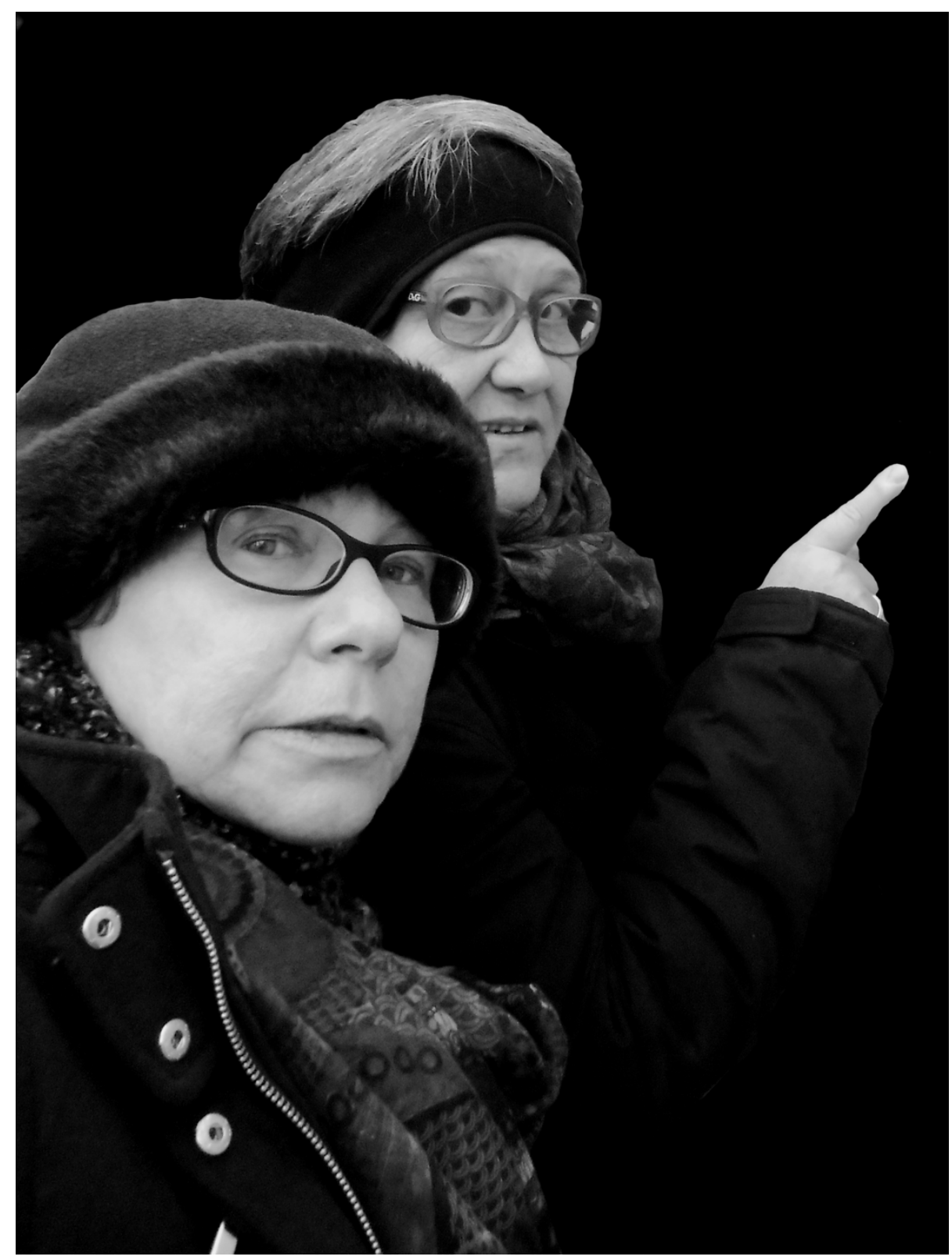

Figura 2: Profa. Dra. Cornelia Eckert e Profa. Dra. Ana Luiza Carvalho da Rocha 
Bruno e Guarín: Quase dois séculos depois da invenção das imagens técnicas e hoje no contexto do excesso visual vivido pelas sociedades ocidentais que desafios antropológicos estão implicados no trabalho de pesquisas com arquivos? O que podemos pensar sobre arquivos de imagens no futuro?

Eckert e Rocha: A velocidade com que as mídias se transformam é estonteante. Mas não somente as mídias se complexificam, elas também promovem um movimento de massificação de acesso tanto quando de democratização. O nosso esforço de pesquisar nas mídias, se trata de uma tentativa, ainda que modesta, de disponibilizar o conhecimento científico acumulado por nós e nossos colaboradores e bolsistas nas pesquisas sobre os itinerários de grupos urbanos, a memória coletiva e formas de sociabilidade no mundo contemporâneo, originalmente criado nos muros universitários, para um público mais amplo.

Isso não quer dizer que as desigualdades estejam superadas. A forma como populações carentes acessam as novas tecnologias, certamente é bem diferenciada do acesso da elite. Mas hoje já temos educação à distância, por exemplo, permitindo uma interiorização da educação tanto quando o acesso à globalização e internacionalização da educação.

$\mathrm{Na}$ Antropologia, o resgate de coleções de populações tradicionais tem permitido a estas o reencontro com sua cosmologia, seus símbolos míticos. Os museus antropológicos no Brasil apostavam muito nesta devolução do conhecimento aos povos indígenas e quilombolas, por exemplo. O incêndio do Museu Nacional evidenciou a fragilidade em que se encontram acervos milenares. As instituições não têm as condições necessárias para seu resguardo, por falta de financiamento e investimento nas políticas culturais. Certamente os arquivos das imagens deste patrimônio são um alento, porém não superam a eternidade do objeto símbolo da trajetória humana. Mas, sem dúvida, a era digital promete ser expansiva e eterniza nossas criações em um museu do imaginário.

Bruno e Guarín: E o que dizer sobre o potencial de pesquisas e temas antropológicos destinados a arquivos ordinários, muitas vezes anônimos, mas reveladores de outras histórias "mudas" e não catalogadas? Que desafios estes arquivos impõem a um saber antropológico em direção a outro tipo de metodologia de trabalho com as imagens? 
Eckert e Rocha: Os arquivos anônimos, ordinários, são de modo geral revelados a partir de pesquisas etnográficas consentidas, detalhados a partir de uma interlocução com o detentor do arquivo, autor(a) do saber. Não necessariamente todos os arquivos anônimos devam ser expostos, revelados. Alguns talvez, repletos de segredos, devam ser respeitados neste formato, ao menos por várias gerações até seu desaparecimento ou sua recuperação para o uso ou para a pesquisa. Mas, de modo geral, a monografia, como dizia Louis Dumont, tem o potencial de trazer à superfície, estas memórias e vidas narradas. A Antropologia Visual de modo singular tem produzido pesquisa e circulado este conhecimento com muita inventividade. Ousando para além dos cânones da escrita, tem divulgado a produção de conhecimento em diferentes suportes, como por exemplo, um varal de fotos na rua de uma população estudada, ou através de vídeos, exposições, e sobretudo recursos digitais, que testemunham a descontinuidade dos tempos, as múltiplas rítmicas da humanidade em suas diversidades e em suas identidades.

\section{REFERÊNCIAS}

SAMAIN, Etienne. “Quando a fotografia (já) fazia os antropólogos sonharem: O jornal La Lumière (1851-1860)". Revista de Antropologia, 44(2), 89-126, 2001. https://doi.org/10.1590/S0034-77012001000200003

SAMAIN, Etienne. "Bronislaw Malinowski e a fotografia antropológica", in Pluralismo, espaço social e pesquisa, São Paulo, ANPOCS/Hucitec, pp. 287-321, 1995. SAMAIN, Etienne. "Ver e dizer na tradição etnográfica: Bronislaw Malinowski e a fotografia". Samain, Etienne. In: Revista Horizontes Antropológicos, Porto Alegre, UFRGS, ano 1, n. 2, p. 23-60, jul-set 1995.

BATESON, Gregory; MEAD, Margaret. Balinese Character: A Photografic Analysis. New York: New York Academy of Sciences, 1942. 
CAIUBY NOVAES, Sylvia (org.). Entre arte e ciência: a fotografia na antropologia. São Paulo: Edusp, 2015.

CAIUBY NOVAES, Sylvia. "Lévi-Strauss, razão e sensibilidade" In Revista de Antropologia 42, 1-2. São Paulo, 1999.

LÉVI-STRAUSS, Claude. Tristes trópicos. São Paulo: Companhia das Letras, 1996. . Saudades do Brasil. São Paulo: Companhia das Letras, 1994.

Recebido: $05 / 08 / 2020$

Aprovado: $07 / 08 / 2020$ 